\title{
Auditory sensitivity and the outer hair cell system in the CBA mouse model of age-related hearing loss
}

This article was published in the following Dove Press journal:

Open Access Animal Physiology

3 June 2010

Number of times this article has been viewed

\author{
Robert D Frisina \\ Xiaoxia Zhu \\ Otolaryngology, Biomedical \\ Engineering, Neurobiology, and \\ Anatomy Departments, University of \\ Rochester School of Medicine and \\ Dentistry, Rochester, New York, USA
}

\begin{abstract}
Age-related hearing loss is a highly prevalent sensory disorder, from both the clinical and animal model perspectives. Understanding of the neurophysiologic, structural, and molecular biologic bases of age-related hearing loss will facilitate development of biomedical therapeutic interventions to prevent, slow, or reverse its progression. Thus, increased understanding of relationships between aging of the cochlear (auditory portion of the inner ear) hair cell system and decline in overall hearing ability is necessary. The goal of the present investigation was to test the hypothesis that there would be correlations between physiologic measures of outer hair cell function (otoacoustic emission levels) and hearing sensitivity (auditory brainstem response thresholds), starting in middle age. For the CBA mouse, a useful animal model of age-related hearing loss, it was found that correlations between these two hearing measures occurred only for high sound frequencies in middle age. However, in old age, a correlation was observed across the entire mouse range of hearing. These findings have implications for improved early detection of progression of age-related hearing loss in middle-aged mammals, including mice and humans, and distinguishing peripheral etiologies from central auditory system decline.
\end{abstract}

Keywords: presbycusis, hearing loss, hair cells, auditory brainstem response, otoacoustic emissions, mouse hearing

\section{Introduction}

Presbycusis, or age-related hearing loss, is highly prevalent clinically and in laboratory animals. In human populations, presbycusis is the leading communication disorder and one of the top three chronic medical conditions in the elderly. Understanding the physiologic, anatomic, and molecular bases of the degeneration of the aging inner ear and brain will pave the way for future biomedical interventions. These will include application of drugs or therapeutic compounds to prevent, slow, or reverse the progression of age-related hearing loss.

These biomedical translational goals underscore the importance of having a full appreciation of the characteristics and time course of deficits in mammalian animal models used in studying the progression of presbycusis. Different species have been utilized to study the biologic bases of age-related hearing loss, for example, gerbils ${ }^{1-2}$ and rats, ${ }^{3-10}$ and several mouse strains have proven to be quite useful. ${ }^{11-21}$ Advantages of using mice include a comprehensive understanding of the mouse genome, the relative ease of creating knockout mice, and the successful production of knockins and transgenics.

In the field of sensory aging, several mouse strains have furthered progress in a noteworthy manner. C57Bl/6 (Black 6) mice, the favorite background strain for knockout
Correspondence: Robert Frisina Department of Otolaryngology, University of Rochester Medical Center 60I Elmwood Avenue, Rochester, NY 14642-8629, USA

$\mathrm{Tel}+\mathrm{I} 5852758$ I30

Fax + I 585 27| 8552

Email robertfrisina@urmc.rochester.edu 
mice in general, possess a prominent, high-frequency, accelerated age-related hearing loss, wherein middle-aged mice have severe-to-profound hearing impairment. ${ }^{22-25}$ These mice have been a particularly valuable model for examining brain changes and plasticity that result from loss of output channels from an aging auditory inner ear-cochlea. ${ }^{26-30}$

The CBA strain that, like most humans, loses its hearing on a more gradual time course has also proved to be quite valuable. ${ }^{31}$ For example, middle-aged and older CBA mice display auditory temporal processing alterations that appear to be primarily a result of brainstem neural processing changes, rather than being driven directly by peripheral deafferentation that occurs, in contrast, in Black 6 mice. ${ }^{32-36}$ Studies of the CBA aging auditory system have also revealed significant decline in the physiology of the feedback system from the auditory brainstem to the cochlea, beginning in middle age, ${ }^{37-38}$ similar to what has been discovered in aging human listeners. ${ }^{39}$ Voltage-gated potassium channels are important for cochlear and brainstem auditory physiologic processing. Decline in the auditory efferent feedback system is related to aging changes in the expression of voltage-gated potassium channels in the brainstem regions containing the cell bodies of the auditory efferent feedback neurons. ${ }^{40}$ Surprisingly, the F1 generation of a Black $6 \times$ CBA cross has been shown to have superior hearing to either parental strain. ${ }^{41}$

In most cases of hearing loss, outer hair cells are most sensitive to ototoxic insults and precede the loss of inner hair cells. When outer hair cells are lost, decreases occur in the overall sensitivity of the auditory system. To expand the usefulness of the CBA mouse strain for improving our understanding of the neural changes that take place in the cochlea with age, it is important to delineate the relationship between age changes in the hair cell system and overall changes in auditory physiologic sensitivity. It was hypothesized in the present investigation that, beginning in middle age, there would be correlations between measures of physiologic measures of the health and well being of the cochlear outer hair cell system and physiologic recordings of the overall sensitivity of hearing. To test this hypothesis, we compared auditory brainstem response (ABR) threshold shifts, a measure of overall sensitivity to sound to distortion-product otoacoustic emission (DPOAE) amplitude level shifts, a physiologic measure of outer hair cell function in young, middle-aged, and old CBA mice.

\section{Methods}

\section{Subjects}

All mice were bred in-house, and housed according to institutional protocols, with original breeding pairs obtained from Jackson Laboratories. For this very large cross-sectional study, adult CBA mice were divided into three groups according to age, ie, young adult ( $\mathrm{n}=115$, aged 1.5-4 months), middle-aged ( $\mathrm{n}=126,11-16$ months), and old ( $n=86,22-34$ months). Note that 40 of the mice used in the present investigation were also used in a previous highthroughput gene microarray study. ${ }^{46-47}$ All animal procedures were approved by the University of Rochester Committee on Animal Resources and are consistent with NIH guidelines.

\section{Auditory brainstem responses}

The ABR and DPOAE testing procedures were similar to those used in our previous reports, ${ }^{38,40-43}$ and are summarized here. Prior to data acquisition, individual mice were microscopically examined for evidence of external ear canal and middle ear obstruction. Mice with clearly visualized, healthy tympanic membranes were included. ABRs were recorded with subcutaneous platinum needle electrodes placed at the vertex (non-inverting input), right mastoid prominence (inverted input), and tail (indifferent site). Calibrated tone pips of $5 \mathrm{msec}$ duration and $0.5 \mathrm{msec}$ rise-fall time (phase alternating $90^{\circ}$ ) were utilized. Electroencephalographic (EEG) activity was differentially amplified $(50 \times$ or $100 \times$; Grass [Quincy, MA] model P511 EEG amplifier), then input to an A/D converter (Tucker-Davis Technologies [TDT, Alachua, FL] AD1), and digitized at $50 \mathrm{kHz}$. Each averaged response was based on 300-500 stimulus repetitions recorded over $10 \mathrm{msec}$ epochs. Contamination by muscle or cardiac activity was prevented by rejecting data epochs in which the single-trace EEG contained peak-to-peak amplitudes exceeding $50 \mu \mathrm{V}$. The threshold was defined as the first level that did not evoke a response to a measured frequency, ie, no difference from the baseline. During this procedure an intraperitoneal general anesthetic was used. Normal body temperature was maintained at $38^{\circ} \mathrm{C}$ with a servo heating pad. The ABR was recorded in a small sound attenuating chamber (IAC).

\section{Distortion-product otoacoustic emissions}

Mice were anesthetized with ketamine-xylazine (120 and $10 \mathrm{mg} / \mathrm{kg}$ body weight, respectively) by intraperitoneal injection before experimental sessions. All recording sessions were completed in a soundproof acoustic chamber (IAC lined with Sonex) with body temperature maintained with a heating pad. Before recording, the stimulus probe and microphone coupler were placed in the test ear near the tympanic membrane with the aid of an operating stereoscope. 
Ipsilateral acoustic stimulation and simultaneous measurement of DPOAEs was accomplished with aTDT BioSig System III. Stimuli were digitally synthesized at $200 \mathrm{kHz}$ using SigGen software with the ratio of $f 2 / f 1$ constant at 1.25 , and $L 1=65 \mathrm{~dB}$ and $L 2=50 \mathrm{~dB}$ SPL, as calibrated in a $0.1 \mathrm{cc}$ coupler simulating the mouse ear canal. Signal duration was $84 \mathrm{msec}$ and repetition rate was $21 / \mathrm{sec}$. After synthesis, $f 1$ and $f 2$ were each passed through an RP2.1 D/A converter to PA5 programmable attenuators. Following attenuation, the signals went to ED1 speaker drivers which fed into the EC1 electrostatic loudspeakers coupled to the ear canal via short flexible tubes with rigid plastic tapering tips. For DPOAE measurements, the resulting ear canal sound pressure was recorded with an ER10B+ low noise microphone (gain 20x) and probe (Etymotic, Elk Grove Village, IL) housed in the same coupler as the $f 1$ and $f 2$ speakers. The output of the ER10B+ amplifier was input to an MA3 microphone amplifier, the output of which went to an RP2.1 A/D converter for sampling at $200 \mathrm{kHz}$. A fast Fourier transform (FFT) was performed on the resultant waveform. The magnitude of $f 1, f 2$, the $2 f 1-f 2$ distortion product, and the noise floor of the frequency bins surrounding the $2 f 1-f 2$ component were measured from the FFT. The procedure was repeated for geometric mean frequencies ranging from 5.6 to $44.8 \mathrm{kHz}$ ( 8 frequencies/octave) to assess adequately the neuroethologically functional range of mouse hearing. Duration of the testing was approximately one hour per animal.

\section{Statistical analysis}

The hearing of young adult mice was measured via ABRs and DPOAEs. These measurements served as the reference for comparison with the middle-aged and old subject groups. The statistical analyses were performed with PRISM $^{\circledR} 4.0$ (GraphPad Software, San Diego, CA). Linear regressions were conducted to analyze the correlations between ABR thresholds $(3,6,12,24,32$, and $48 \mathrm{kHz})$ and DPOAE levels in different frequency bands (low $4-15 \mathrm{kHz}$, middle $15-30 \mathrm{kHz}$, high $30-48 \mathrm{kHz}$ ) for the three different subject groups. Also, two-way analysis of variance (ANOVAs) was preformed for subject group mean data at different frequencies, and followed by Bonferroni post hoc t-tests, that were corrected for multiple comparisons. Error bars indicate standard error of the mean (SEM) unless otherwise stated.

\section{Results}

\section{Auditory brainstem response thresholds}

The overall sensitivity of the auditory system lessened with age, as shown in Figure 1. There were statistically significant differences between the old mice and the other age groups. Also evident was a significant increase in the variability of the thresholds at each frequency with age, as indicated by the larger error bars for the old mice (Figure 1A). The two-way ANOVA main effects for aging and frequency were significant: Age $\mathrm{F}(2,5)=1335, P<0.0001$; frequency $\mathrm{F}(2,5)=588, P<0.0001$. Bonferroni post hoc tests showed significant differences between the ABR thresholds for the young adults and the two older age groups, as shown in the Table.

\section{Otoacoustic emission levels}

The physiology of the outer hair cell system declined with age, particularly in the old mice, as presented in Figure 2. When the DPOAE amplitude levels for the old group were compared with those for young adults, a significant difference was present using two-way ANOVA for aging $\times$ frequency: Age $\mathrm{F}(2,24)=2837, P<0.0001$; frequency $\mathrm{F}(2,24)=250$, $P<0.0001$. Bonferroni multiple comparison tests revealed significant differences across all frequencies for the young adult versus the aged group; $t$ values ranged from 5.7 to 20.79 , $P<0.001$. Like the ABRs, noticeable increases in variability take place at each frequency measured for the old mice
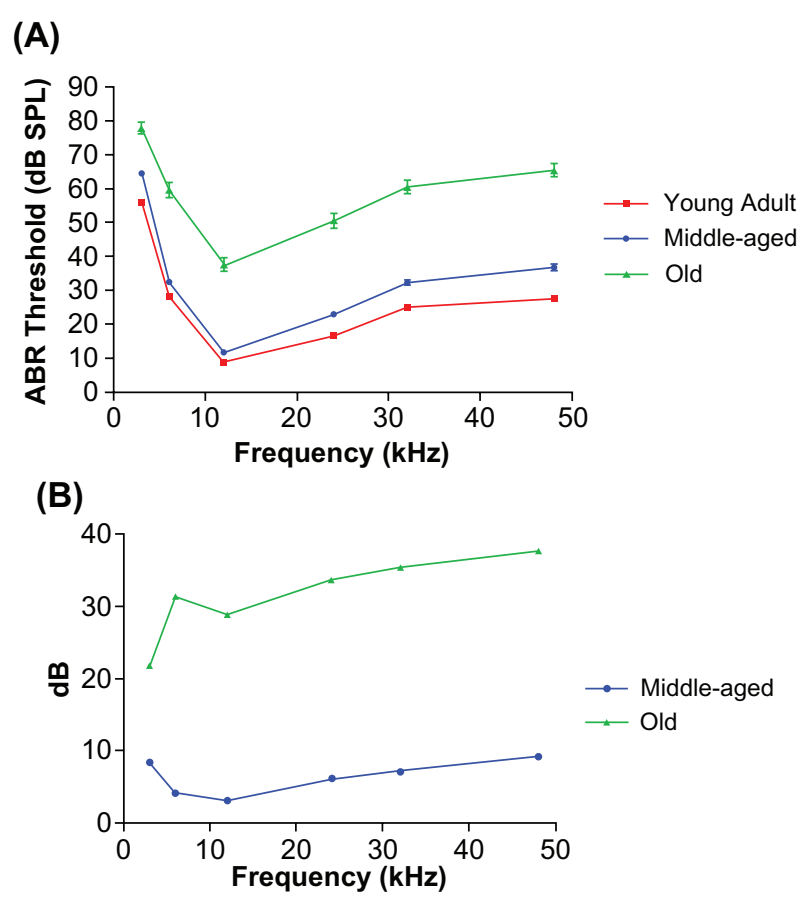

Figure I Comparisons of ABR thresholds in three mouse age groups. A) Frequency threshold curves for the young adult and middle ages were similar, but a large threshold elevation occurred in old age. The variability of the responses showed a marked increase in the old group, as evidenced by the larger error bars. B) ABR threshold shift comparisons between young adult CBA mice and the two older age groups. The middle-aged mice had thresholds within about $10 \mathrm{~dB}$ of the young adults. The old group had 22-38 dB ABR threshold elevations compared with young adults. Both of the older subject groups displayed a high frequency hearing loss.

Abbreviation: ABR auditory, brainstem response. 
Table I Bonferroni post hoc pairwise comparisons of ABR thresholds

\begin{tabular}{|c|c|c|c|c|}
\hline & \multicolumn{2}{|c|}{ Young adult versus middle age } & \multicolumn{2}{|c|}{ Young adult versus old age } \\
\hline & $\mathbf{t}$ & $P$ value & $\mathbf{t}$ & $P$ value \\
\hline $3 \mathrm{kHz}$ & 5.715 & $P<0.001$ & 13.31 & $P<0.001$ \\
\hline $6 \mathrm{kHz}$ & 2.831 & $P<0.05$ & 19.13 & $P<0.001$ \\
\hline $12 \mathrm{kHz}$ & 2.06 & NS & 17.6 & $P<0.001$ \\
\hline $24 \mathrm{kHz}$ & 4.094 & $P<0.001$ & 20.58 & $P<0.001$ \\
\hline $32 \mathrm{kHz}$ & 4.865 & $P<0.001$ & 21.62 & $P<0.001$ \\
\hline $48 \mathrm{kHz}$ & 6.187 & $P<0.001$ & 23.0 & $P<0.001$ \\
\hline
\end{tabular}

Abbreviations: $A B R$, auditory brainstem response; NS, not statistically significant.

relative to the younger age groups (larger error bars for the old mice in Figure 2A). Also, the young adults versus the middleaged mice showed significant differences above $35 \mathrm{kHz}$, with $\mathrm{t}$ values ranging from 3.268 to $3.514, P<0.05$. As with the ABRs (Figure 1B), the greatest change was between the middle-aged and old mice, as shown in Figure 2B.

\section{High-frequency changes begin in middle age}

The quantitative relations between the extent of outer hair cell system declines with age, and the progression of the deficits in overall auditory sensitivity comprised the next part of the investigation. Linear regression analyses were performed for

(A)

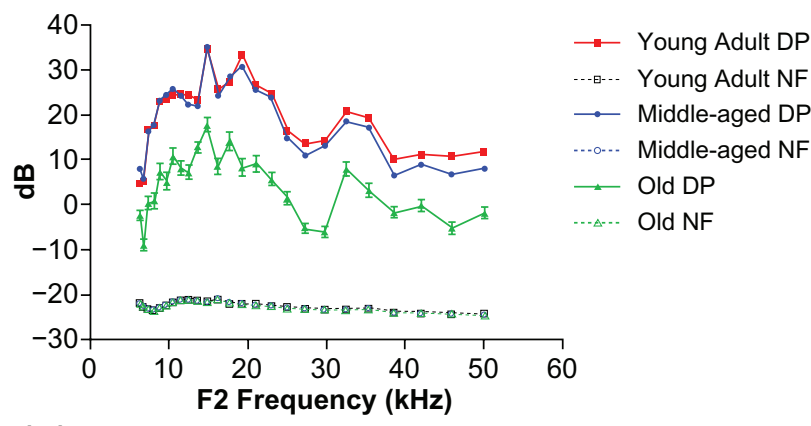

(B)

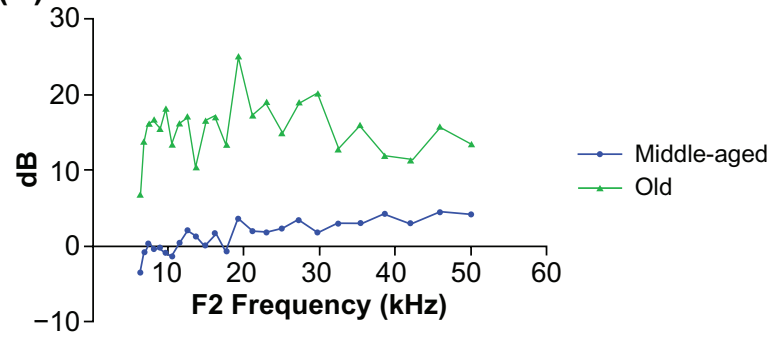

Figure 2 The DPOAE-grams reveal significant differences between the old subjects and the other two age groups. A) DPOAE levels were similar between the young adults and middle-aged mice, but large declines occurred in old age. Note the larger error bars in the oldest group. B) DPOAE level shifts compared with young adult: the middle-aged subjects showed a $2-5 \mathrm{~dB}$ change in the middle and high frequencies of the mouse hearing range, but there were large 10-25 dB shifts for the old group. Abbreviations: DP, distortion product; DPOAE, distortion-product otoacoustic emission; NF, noise floor. each stimulus frequency region, throughout the full range of mouse hearing. For measurements in the middle-aged mice, it was only in the highest frequency region of hearing that a significant correlation was found between the physiologic measures of the cochlear outer hair cell system and overall sensitivity to sound, as plotted in Figure 3A. Consistent with this, in the older age group, the highest correlation between the two measures was in the highest frequency range, as presented in Figure 3B.

\section{Frequency-specific relations in old age}

Although the correlation coefficients were modest, significant correlations were also discovered when comparisons were made for all of the frequency ranges covering the mouse audiogram in the old animals, as presented in Figure 4. Note that the correlation was strongest for the highest frequency range tested (see Figure 3B for comparison with the other frequency bands presented in Figure 4).

\section{Overall relationships in middle-aged and old mice}

Linear regressions were conducted to test for significant correlations between ABR thresholds and DPOAE levels across all frequencies of the mouse audiogram, as presented in Figure 5. In middle-aged mice, a significant relationship held, most likely driven by the high frequency data, as presented above (Figure 3A). Not surprisingly, a significant correlation was observed when the data from the old subjects were pooled across all of the frequencies, because the data for each of the individual frequency ranges analyzed were statistically significant, as presented in Figures 3B and 4. Because young adults had uniformly good hearing, there were no significant relationships between the two measures (data not shown).

\section{Discussion}

The present study, consisting of a large sample of subjects in each group relative to prior animal model investigations of the aging auditory system, found that the overall sensitivity 


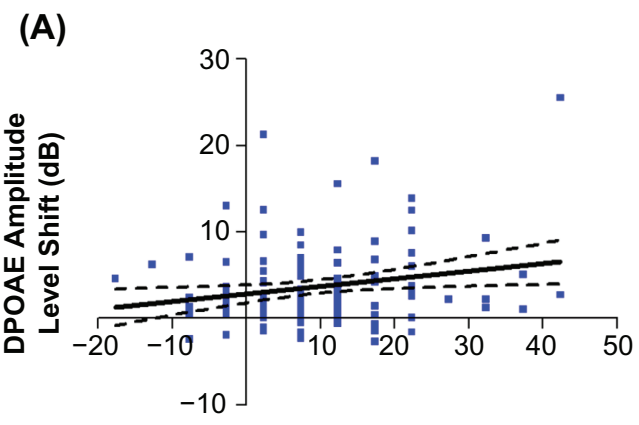

ABRs Threshold Shift (dB)

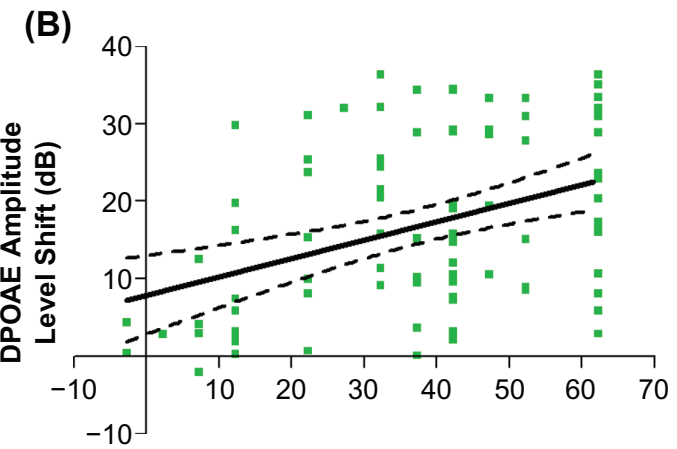

ABRs Threshold Shift (dB)

Figure 3 Group correlations between decline in the outer hair cell system and overall auditory sensitivity start to occur in middle age. A) Correlations between $A B R$ thresholds and DPOAE level shifts are significant, only at the high frequencies (30-50 kHz) in middle age: $F(I, I 24)=5.32, P=0.0228, r^{2}=0.04 I I$. B) The correlations in the high frequency range become much stronger in old age: $F(I, 84)=\mid 5.21$, $P=0.0002, r^{2}=0.1533$. Here, and in the remaining figures, dashed lines in the regression plots represent $95 \%$ confidence intervals.

Abbreviations: $A B R$, auditory brainstem response; DPOAE, distortion-product otoacoustic emission.

of the system diminished with age, consistent with previous research involving smaller numbers of subjects. ${ }^{20,22-26,37,38,41,43}$ Consistent with both physiologic and anatomic investigations of the cochlea, the outer hair cell system also declined with age, starting in the middle-age years. ${ }^{44,45}$ One feature of these changes in CBA mice that appears in multiple studies is that age-related deficits are generally larger when comparing middle-aged with old mice than the changes seen when comparing the hearing of young adults with middle-aged subjects. ${ }^{46,47}$ Also, consistent with most previous aging studies, the variability of the physiologic measures reported here show increases with age, as indicated by the larger error bars for the old mice displayed in Figures 1 and 2.

Age changes in sensory systems can be due to environmental factors such as intense stimuli (eg, loud noise), and drugs including antibiotics or chemotherapeutic agents, or may be due to aging changes inherent in the peripheral sensory organs (ear, eye) or parts of the brain used for sensory processing. Currently, the leading theory for "pure" aging in the cochlea implicates different components of the endolymph $/ \mathrm{K}^{+}$recycling system. The stria vascularis

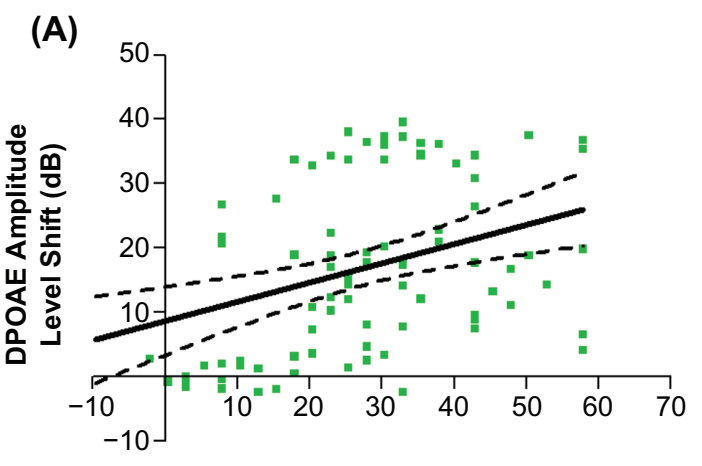

ABRs Threshold Shift (dB)

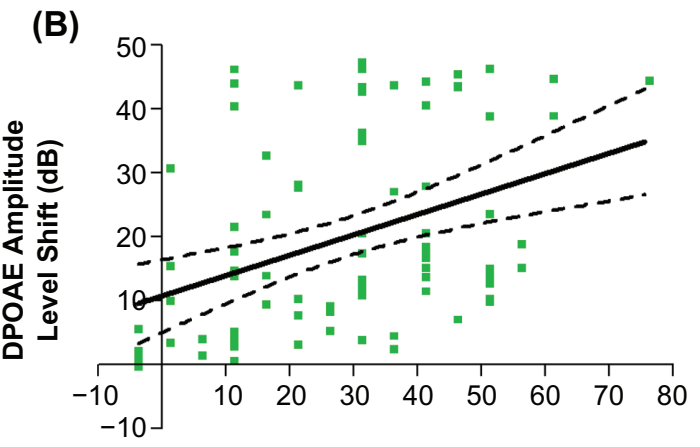

ABRs Threshold Shift (dB)

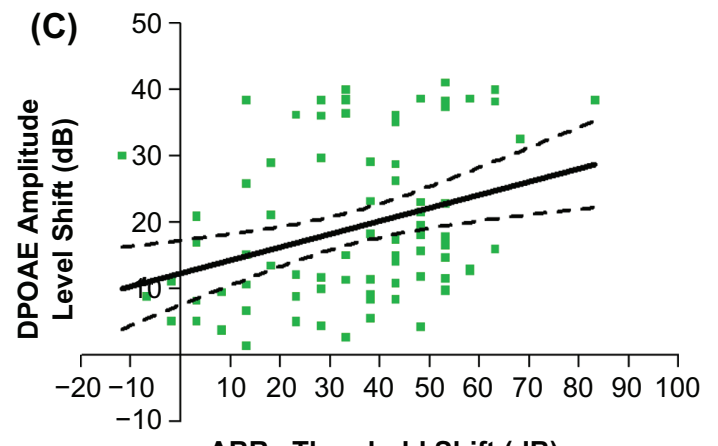

ABRs Threshold Shift (dB)

(D) Correlations for $30-40 \mathrm{kHz}$ Sounds in Old Age CBAs

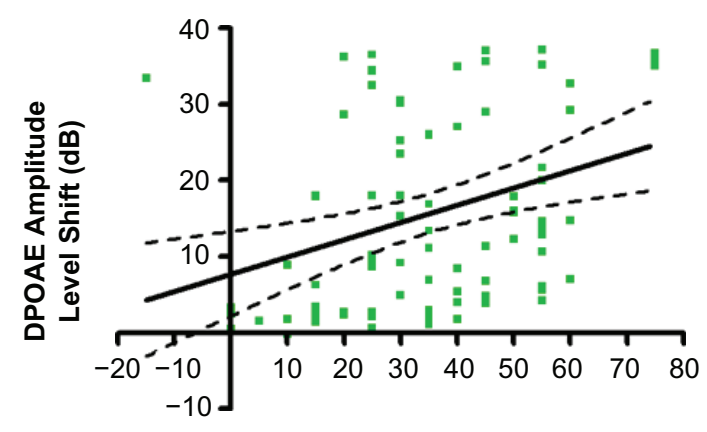

ABRs Threshold Shift (dB)

Figure 4 In old age, regression analyses yielded significant relationships between otoacoustic emission levels and $A B R$ thresholds for all of the frequency bands tested. A) $I-10 \mathrm{kHz}, \mathrm{F}(\mathrm{I}, 84)=12.90, P=0.0006, \mathrm{r}^{2}=0.1331$. B) $10-20 \mathrm{kHz}, \mathrm{F}(\mathrm{I}, 84)=14.64$, $P=0.0002, r^{2}=0.1484$. C) $20-30 \mathrm{kHz}, \mathrm{F}(1,84)=10.08, P=0.0021, r^{2}=0.1071$. D) $30-40 \mathrm{kHz}, \mathrm{F}(\mathrm{I}, 84)=10.70, P=0.0016, \mathrm{r}^{2}=0.1130$.

Abbreviation: $A B R$, auditory brainstem response. 


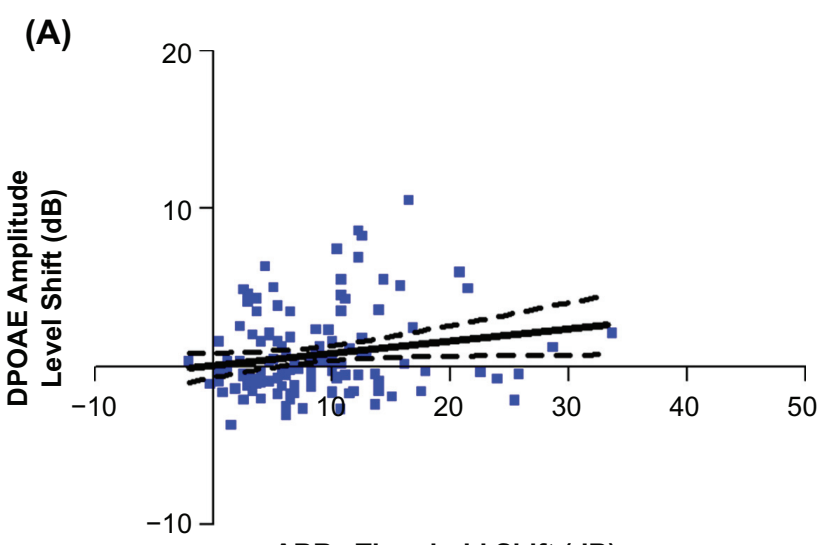

ABRs Threshold Shift (dB)

(B)

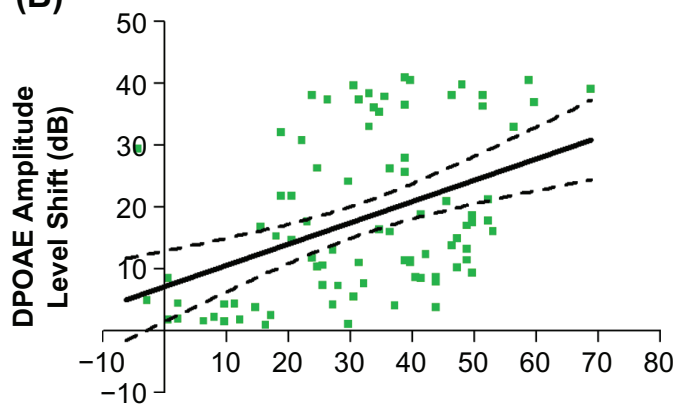

ABRs Threshold Shift (dB)

Figure 5 Correlations between $A B R$ thresholds and DPOAE levels across the entire hearing range for mice of different ages. A) Correlations for the middle age mice were present, but not as striking as in old age: $\mathrm{F}(\mathrm{I}, 124)=4.22, P=0.042, \mathrm{r}^{2}=0.033$. B) A greater relationship was observed in the old mice: $F(I, 84)=18.43, P<0.000 \mathrm{I}$, $r^{2}=0.18$. Note: Since young adults all had excellent hearing, there were no significant relationships.

Abbreviations: ABR, auditory brain stem response; DPOAE, distortion-product otoacoustic emission.

is the specialized trilaminar organ located on the lateral wall of the scala media, the fluid-filled cavity of the cochlea that bathes the tops of the hair cells with $\mathrm{K}^{+}$rich endolymph. ${ }^{48,49}$ Evidence from the gerbil animal model of presbycusis suggests that natural cochlear aging is in large part due to age-linked pathology of the stria vascularis, causing the endolymph-rich "cochlear battery" (endocochlear potential) to discharge with age. ${ }^{50-60}$ Depletion of the $\mathrm{K}^{+}$concentration and endocochlear potential in the scala media interferes with the normal exquisite sensitivity of the cochlear hair cell sound transduction mechanisms, resulting in a decline in otoacoustic emission amplitudes and elevation of ABR thresholds. Additional evidence from mouse models indicates that other parts of the cochlear $\mathrm{K}^{+}$processing system also become impaired with age, including different aspects of the scala media lateral wall, such as the Type IV fibrocytes. ${ }^{61-64}$ Age deficits in the cochlear endolymph $\mathrm{K}^{+}$system tend to cover a wide range of sound frequencies, because the endolymph can diffuse with relatively little fluid resistance from the cochlear base to the apex. In light of this, correlations across the entire mouse hearing range, reported in the present investigation for old mice, suggest that the physiologic decline of the aged cochlea is likely linked to deficits in the stria vascularis $/ \mathrm{K}^{+}$cycling system of the old cochlea, that are not as prevalent in middle-aged mice.

Contributions of the present investigation include new delineations of the quantitative relationships between physiologically measured aging deficits in cochlear outer hair cell responses and the overall sensitivity of the auditory system, occurring in a very useful mouse model for investigations of presbycusis. ${ }^{14,16,17}$ For middle-aged mice, correlations were seen only in the high frequencies. This indicates that for the lower and middle frequency regions of mouse hearing, middle-aged mice that have age-related deficits in the outer hair cell system are not the same mice showing the largest decline in their overall hearing sensitivity. Therefore, the relationship between these two physiologic hearing measures does not reveal itself widely until old age.

\section{Summary and conclusions}

This study demonstrates that correlations between ABR thresholds and DPOAE levels become more significant with age, extending throughout the entire frequency range of hearing in old mice. This suggests that decline in the outer hair cell system of the auditory periphery become a greater determinant of overall auditory sensitivity with age. In addition, the physiologic measurement of otoacoustic emissions is now the most widespread clinical screening measure for detecting hearing loss and deafness in newborn infants. One implication of the present investigation is that for clinical detection or diagnosis of age-related hearing loss, the noninvasive DPOAE-level testing paradigm utilizing high frequency sounds as probe stimuli may be a valuable method for early detection of presbycusis in middle-aged listeners. Earlier detection and diagnosis of age-related hearing loss is a necessary prerequisite for maximizing effectiveness of biomedical interventions aimed at preventing this highly prevalent form of sensory impairment.

\section{Acknowledgements}

We thank Dr Robert Frisina Sr. for valuable critiques and discussion, John Housel for technical assistance, and Enza Daugherty for project support. Supported by NIH grants P01 AG09524 from the National Institute on Aging and P30 DC05409 from the National Institute on Deafness and Communication Disorders, and the International Center for Hearing and Speech Research, Rochester, New York. 


\section{Disclosures}

The authors report no conflicts of interest in this work.

\section{References}

1. Schmiedt RA, Lang H, Okamura H, Schulte BA. Effects of furosemide applied chronically to the round window: A model of metabolic presbycusis. $J$ Neurosci. 2002;22:9643-9650.

2. Lang H, Schulte BA, Schmiedt RA. Effects of chronic furosemide treatment and age on cell division in the adult gerbil inner ear. $J$ Assoc Res Otolaryngol. 2003;4:164-175.

3. Casey MA, Feldman ML. Aging in the rat medial nucleus of the trapezoid body. I. Light microscopy. Neurobiol Aging. 1982;3:187-195.

4. Caspary DM, Milbrandt JC, Helfert RH. Central auditory aging: GABA changes in the inferior colliculus. Exp Gerontol. 1995;30: 349-360.

5. Caspary DM, Raza A, Lawhorn Armour BA, Pippin J, Arneric SP. Immunocytochemical and neurochemical evidence for age-related loss of GABA in the inferior colliculus: Implications for neural presbycusis. J Neurosci. 1990;10:2363-2372.

6. Faingold CL, Gehlbach G, Caspary DM. On the role of GABA as an inhibitory neurotransmitter in inferior colliculus neurons: Iontophoretic studies. Brain Res. 1989;500:302-312.

7. Milbrandt JC, Albin RL, Caspary DM. Age-related decrease in GABAB receptor binding in the Fischer 344 rat inferior colliculus. Neurobiol Aging. 1994;15:699-703.

8. Milbrandt JC, Caspary DM. Age-related reduction of [3H]strychnine binding sites in the cochlear nucleus of Fischer 344 rat. Neurosci. 1995;67:713-719.

9. Milbrandt JC, Hunter C, Caspary DM. Alterations of GABAA receptor subunit mRNA levels in the aging Fischer 344 rat inferior colliculus. J Comp Neurol. 1997;379:455-465.

10. Syka J. Plastic changes in the central auditory system after hearing loss, restoration of function, and during learning. Physiol Rev. 2002;82: 601-636.

11. Henry KR, Chole RA. Genotypic differences in behavioral, physiological and anatomical expressions of age-related hearing loss in the laboratory mouse. Audiol. 1980;19:369-383.

12. Hunter KP, Willott JF. Aging and the auditory brainstem response in mice with severe or minimal presbycusis. Hear Res. 1987;30: 207-218.

13. Jimenez AM, Stagner BB, Martin GK, Lonsbury-Martin BL. Age-related loss of distortion-product otoacoustic emissions in four mouse strains. Hear Res. 1999;138:91-105.

14. Le Calvez S, Avan P, Gilain L, Romand R. CDI hearing-impaired mice. I: Distortion-product otoacoustic emission levels, cochlear function and morphology. Hear Res. 1998;120:37-50.

15. Li HS, Borg E. Age-related loss of auditory sensitivity in two genotypes. Acta Otolaryngol. 1991;111:827-834.

16. Parham K. Distortion product otoacoustic emissions in the C57BL/6J mouse model of age-related hearing loss. Hear Res. 1997;112:216-34.

17. Parham K, Sun X-M, Kim DO. Distortion product otoacoustic emissions in the CBA/J mouse model of presbycusis. Hear Res. 1999;134:29-38

18. Parham K, Sun X-M, Kim, DO. Noninvasive assessment of auditory function in mice: Auditory brainstem response and distortion product otoacoustic emissions. In: Willott JF, editor. Handbook of Mouse Auditory Research. Boca Raton, FL: CRC Press; 2001.

19. Willott J. Aging in the Auditory System: Anatomy, Physiology, and Psychophysics. San Diego: Singular Publishing Group, Inc.; 1991.

20. Willott JF, Chisolm TH, Lister JJ. Modulation of presbycusis: Current status and future directions. Audiol Neurootol. 2001;6: 231-249.

21. Willott JF, Bosch JV, Shimizu T, Ding DL. Effects of exposing DBA/2J mice to a high-frequency augmented acoustic environment on the cochlea and anteroventral cochlear nucleus. Hear Res. 2006;216:138-145.
22. Willott JF, Bross LS. Morphology of the octopus cell area of the cochlear nucleus in young and aging C57BL/6J and CBA/J mice. J Comp Neurol. 1990;300:61-81.

23. Willott JF, Bross LS. Morphological changes in the anteroventral cochlear nucleus that accompany sensorineural hearing loss in DBA/2J and C57BL/6J mice. Dev Brain Res. 1996;91:218-26.

24. Willott JF, Bross LS, McFadden SL . Morphology of the dorsal cochlear nucleus in C57BL/6J and CBA/J mice across the life span. $J$ Comp Neurol. 1992;321:666-678.

25. Willott JF, Carlson S. Modification of the acoustic startle response in hearing-impaired C57BL/6J mice: Prepulse augmentation and prolongation of prepulse inhibition. Behav Neurosci. 1995;109:396-403.

26. Kazee AM, Han LY, Spongr VP, Walton JP, Salvi RJ, Flood DG. Synaptic loss in the central nucleus of the inferior colliculus correlates with sensorineural hearing loss in the C57BL/6 mouse model of presbycusis. Hear Res. 1995;89:109-120.

27. Zettel ML, Frisina RD, Haider S, O'Neill WE. Age-related changes in the immunoreactivity of calbindin $\mathrm{D} 28 \mathrm{~K}$ and calretinin in the inferior colliculus of the CBA/J and C57/6J mouse. J Comp Neurol. 1997;386:92-110.

28. Frisina DR, Frisina RD, Snell KB, Burkard R, Walton JP, Ison JR. Auditory temporal processing during aging. In: Hof PR, Mobbs CV, editors. Functional Neurobiology of Aging. San Diego, CA: Academic Press; 2001:565-579.

29. Idrizbegovic E, Bogdanovic N, Viberg A, Canlon B. Auditory peripheral influences on calcium binding protein immunoreactivity in the cochlear nucleus during aging in the C57BL/6J mouse. Hear Res. 2003; $179: 33-42$

30. Idrizbegovic E, Bogdanovic N, Willott JF, Canlon B. Age-related increases in calcium-binding protein immunoreactivity in the cochlear nucleus of hearing impaired C57BL/6J mice. Neurobiol Aging. 2004;25:1085-1093.

31. Sha S-H, Kanicki A, Dootz G, et al. Age-related auditory pathology in the CBA/J mouse. Hear Res. 2008;243:87-94.

32. Walton JP, Frisina RD, Meierhans LR. Sensorineural hearing loss effects recovery from short term adaptation in the CBA and C57 mouse models of presbycusis. Hear Res. 1995;88:19-26.

33. Walton JP, Frisina RD, Ison JR, O'Neill WE. Neural correlates of behavioral gap detection in the inferior colliculus of the young CBA mouse. J Comp Physiol A. 1997;181:161-176.

34. Walton JP, Frisina, RD, O'Neill WE. Age-related alteration in neural processing of silent gaps in the central nucleus of the inferior colliculus in the CBA mouse model of presbycusis. $J$ Neurosci. 1998;18: 2764-2776.

35. Walton JP, Simon H, Frisina RD. Age-related alterations in the neural coding of envelope periodicities. J Neurophysiol. 2002;88:565-78.

36. Simon H, Frisina RD, Walton JP. Age reduces response latency of mouse inferior colliculus neurons to AM sounds. $J$ Acoust Soc Am. 2004;101:469-477.

37. Jacobson M, Kim S-H, Romney J, Zhu X, Frisina RD. Contralateral suppression of distortion-product otoacoustic emissions declines with age: A comparison of findings in CBA mice with human listeners. Laryngoscope. 2003;113:1707-1713.

38. Zhu X, Vasilyeva ON, Kim, SH, et al. Auditory efferent system declines precede age-related hearing loss: Contralateral suppression of otoacoustic emissions in mice. J Comp Neurol. 2007;503:593-604.

39. Kim SH, Frisina DR, Frisina RD. Effects of age on contralateral suppression of distortion-product otoacoustic emissions in human listeners with normal hearing. Audiol Neurootol, 2002;7:348-357.

40. Zettel ML, Zhu X, O’Neill WE, Frisina RD. Age-related declines in $\mathrm{Kv} 3.1 \mathrm{~b}$ expression in the mouse auditory brainstem correlate with functional deficits in the medial olivocochlear efferent system. JAssoc Res Otolaryngol. 2007;8:280-293.

41. Frisina RD, Singh A, Bak M, Bozorg S, Seth R, Zhu X. F1 (CBA x C57) mice show superior hearing in old age relative to their parental strains: Hybrid vigor or a new animal model for "Golden Ears"? Neurobiol Aging. 2009 Oct 28. [Epub ahead of print]. 
42. Frisina RD, Newman SR, Zhu X. Auditory efferent activation in CBA mice exceeds that of C57s for varying levels of noise. J Acoust Soc Am. 2007;121:EL29-34.

43. Price K, Zhu X, Guimaraes P, Vasilyeva ON, Frisina RD. Hormone replacement therapy diminishes hearing in perimenopausal mice. Hearing Res. 2009;252:29-36.

44. Guimaraes P, Zhu X, Cannon T, Kim S-H, Frisina RD. Sex differences in distortion product otoacoustic emissions as a function of age in CBA mice. Hear Res. 2004;192:83-89.

45. Spongr VP, Flood DG, Frisina RD, Salvi RJ. Quantitative measures of hair cell loss in CBA and C57BL/6 mice throughout their life spans. J Acoust Soc Am. 1997;101:3546-3553.

46. Tadros SF, D'Souza M, Zettel ML, Zhu X, Lynch-Erhardt M, Frisina RD. Serotonin 2B receptor: Upregulated with age and hearing loss in mouse auditory system. Neurobiol Aging. 2007;28:1112-1123.

47. Tadros SF, D’Souza M, Zettel ML, Zhu X, Waxmonsky NC, Frisina RD. Glutamate-related gene expression in CBA mouse inferior colliculus changes with age and hearing loss. Brain Res. 2007;1127:1-9.

48. Wangemann P, Liu J, Marcus D. Ion transport mechanisms responsible for $\mathrm{K}^{+}$secretion and the transepithelial voltage across marginal cells of stria vascularis in vitro. Hear Res. 1995;84:19-29.

49. Wangemann P. $\mathrm{K}^{+}$cycling and the endocochlear potential. Hear Res. 2002;165:1-9.

50. Schmiedt RA. Cochlear potentials in quiet-aged gerbils: Does the aging cochlea need a jump start? In: Verrillo RT, editor. Sensory Research: Multimodal Perspectives. Hillsdale, NJ: Lawrence Erlbaum and Associates; 1993.

51. Schmiedt RA. Effects of aging on potassium homeostasis and the endocochlear potential in the gerbil. Hear Res. 1996;102:125-32.

52. Schmiedt RA, Mills JH, Adams JC. Tuning and suppression in auditory nerve fibers of aged gerbils raised in quiet or noise. Hear Res. 1990;45:221-236.

53. Schmiedt RA, Mills JH, Boettcher FA. Age-related loss of activity of auditory-nerve fibers. J Neurophysiol. 1996;76:2799-2803.
54. Schmiedt RA, Lang H, Okamura H-O, Schulte BA. Effects of furosemide chronically applied to the round window: A model of metabolic presbyacusis. J Neurosci. 2002;22:9643-9650.

55. Schulte BA, Schmiedt RA. Lateral wall Na, K-ATPase and endocochlear potentials decline with age in quiet-reared gerbils. Hear Res. 1992;61:35-46.

56. Spicer S, Gratton M, Schulte B. Expression patterns of ion transport enzymes in spiral ligament fibrocytes change in relation to strial atrophy in the aged gerbil cochlea. Hear Res. 1997;111:93-102.

57. Spicer S, Schulte B. Differentiation of inner ear fibrocytes according to their ion transport related activity. Hear Res. 1991;56: 53-64.

58. Spicer S, Schulte B. The fine structure of spiral ligament cells relates to ion return to the stria and varies with place-frequency. Hear Res. 1996;100:80-100.

59. Suryadevara A, Schulte B, Schmiedt R, Slepecky N. Auditory nerve fibers in young and aged gerbils: Morphometric correlations with endocochlear potential. Hear Res. 2001;161:45-53.

60. Tarnowski B, Schmiedt R, Hellstrom L, Lee F, Adams J. Age-related changes in cochleas of Mongolian gerbils. Hear Res. 1991;54: 123-134.

61. Hequembourg S, Liberman MC. Spiral ligament pathology: A major aspect of age-related cochlear degeneration in C57BL/6 mice. J Assoc Res Otolaryngol. 2001;2:118-129.

62. Ohlemiller KK, Gagnon PM. Apical-to-basal gradients in age-related cochlear degeneration and their relationship to "primary" loss of cochlear neurons. J Comp Neurol. 2004;479:103-116.

63. Ohlemiller KK, Lett JM, Gagnon PM. Cellular correlates of age-related endocochlear potential reduction in a mouse model. Hear Res. 2006;220:10-26.

64. Ohlemiller KK, Rybak-Rice ME, Gagnon PM. Strial microvasculature pathology and age-associated endocochlear potential decline in NOD cogenic mice. Hear Res. 2008;244:85-97.
Open Access Animal Physiology

\section{Publish your work in this journal}

Open Access Animal Physiology is an international, peer-reviewed, open access journal publishing original research, reports, reviews and commentaries on all areas of animal physiology. The manuscript management system is completely online and includes a very

\section{Dovepress}

quick and fair peer-review system. Visit http://www.dovepress.com/ testimonials.php to read real quotes from published authors. 